\title{
Editorial: from bulk materials to layered hydroxides: promising aspects of the energy sector
}

\author{
Nitin Chopra \\ Editor-in-chief, Nanomaterials and Energy \\ Associate Professor, Department of Metallurgical and Materials \\ Engineering, The University of Alabama, Tuscaloosa, AL, USA \\ Adjunct Professor, Department of Biological Sciences, The University of \\ Alabama, Tuscaloosa, AL, USA
}

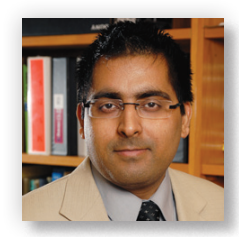

Energy is an important research-and-development sector, bridging the gap between bulk and nanoscale materials as well as linking fundamental energy concepts with socio-geographical issues such as global warming. This issue of Nanomaterials and Energy presents unique results in the area of bulk energy material processing, nanotube, nanowire, nanoparticle synthesis and layered hydroxide materials for energy applications. A feature article by Neelameggham and Davis ${ }^{1}$ focuses on the development of a heat transfer model for explaining anthropogenic warming. It demonstrates that global warming is related to the developed heat transfer model, and indicates the critical role of water vapour in radiation forcing. One benefit of the developed model is that it is less complicated than meteorological modelling and corroborates the role of nanotechnology in clean-energy methods. Also included in this is issue a unique study by Pashinska et al. ${ }^{2}$ which reports the results of bulk aluminum processing using cold rolling with shear. This article emphasises the improvements in manufacturing and modulation of properties by way of controlled nanostructuring. The article by Liyanage et al. ${ }^{3}$ demonstrates patterned electrodeposition of CdTe nanorod and nanotube arrays for solar cells, and the article by Tiwari et al. ${ }^{4}$ demonstrates the facile synthesis of CdSe nanoparticles. Finally, the article by Coluccini et al..$^{5}$ reviews layered double hydroxide materials and their potential for energy applications; such hydroxides are an emerging class of materials for utilisation in this area of research.

This issue of Nanomaterials and Energy shows that the diversity of research in energy and nanostructures reaches far beyond the limitations of conventional nanotechnologies and overlaps with the boundaries of bulk processing and issues of global warming. Additionally, this area of research gives us a unique opportunity to encourage readers to continue submitting their high-quality research on the global platform provided by Nanomaterials and Energy. I would also like to inform our readers about the departure of our managing editor (Ms Sohini Banerjee), whose hard work, efficiency and diligence have been significant in the success of the journal. We also welcome our new managing editor, Dr Sarah Brown, who brings in a great wealth of experience in the area of nanotechnology and journal management. As an editor, I encourage our authors and readers to continue considering Nanomaterials and Energy for publishing their research results and comprehensive reviews. We value our readers and authors, and aim to reach a larger section of energy community.

\section{REFERENCES}

1. Neelameggham, N. R.; Davis, B. Heat transfer modelling of global anthropogenic warming. Nanomaterials and Energy 2014, 3 (5), 149-153.

2. Pashinska, E.; Tkachenko, V.; Burkhovetskiy, V.; Zavdoveev, A.; Varyukhin, V. Structural modification of the aluminum alloy AA1135 by cold rolling with shear. Nanomaterials and Energy 2014, 3 (5), 154-159.

3. Liyanage, W. P. R.; Mishra, S.; Wilson, J. A.; Kinzel, E.; Nath, M. Patterned electrodeposition of CdTe nanorod and nanotube arrays for solar cells. Nanomaterials and Energy 2014, 3 (5), 167-176.

4. Tiwari, A. K.; Verma, V. K.; Jain, T. A.; Bajpai, P. K. A facile route for CdSe nanoparticles: synthesis and structural characterisation. Nanomaterials and Energy 2014, 3 (5), 160-166.

5. Coluccini, C.; Sporer, I.; Leuteritz, A.; Kuehnert, I.; Wang, D.Y. Layered double hydroxide: a new promising nanomaterial in energy application. Nanomaterials and Energy 2014, 3 (5), $177-191$. 